\title{
A Cultural Turn in the Surveillance Studies: Possibilities and Challenges
}

\author{
Nicole Falkenhayner*
}

In the last decade, there has been a growing collective realisation that contemporary lifeworlds, not only in western democratic states, but globally, are structured by multiple and overlapping technologies of control, which extend their reach far beyond institutional concerns into practices of desire, self-expression and "structures of feeling". 1 Surveillance scholar David Lyon has coined the notion of "the culture of surveillance" - for him, surveillance today constitutes nothing less than a "way of life". ${ }^{2}$ In the twenty-fist century, surveillance has become a pervasive aspect of our present due to an entanglement of policies of surveillance and security stemming from the ideology of the 'war on terror' and the rise of a digitalised economical episteme that Soshana Zuboff has called The Age of Surveillance Capitalism. ${ }^{3}$ Accordingly, creative practices ranging from activism and art to literature, film and interactive media have explored venues of the representation and reflection of the current fact of 'inhabiting surveillance' $^{4}$

In turn, the field of Surveillance Studies, which has mapped this development since the 1990s mostly through perspectives of the Social Sciences, has seen a still increasing productivity from various fields of expertise in Cultural Studies. ${ }^{5}$ Connected to the recent interest in theoretical questions of posthumanism and affect within Cultural Studies, critics from film studies, art criticism and literary studies have been involved in the ongoing "work of mapping the diversity of affects, moods and atmospheres of surveillance". ${ }^{6}$ This work offers the possibility to reconfigure what living in "the culture of surveillance" actually means, how it influences our imaginaries, hopes and fears, and ultimately, our forms of subjectivation. The 'cultural turn' in the study of surveillance broadens the perspectives from which knowledge about this concept is produced.

DOI: $10.21552 / \mathrm{edpl} / 2021 / 1 / 4$

* Nicole Falkenhayner is an Associate Professor at the University of Freiburg. For Correspondence: <nicole.falkenhayner@anglistik.uni-freiburg .de>

1 Raymond Williams, Marxism and Literature (2009, OUP)

2 David Lyon, The Culture of Surveillance: Watching as a Way of Life (2018, Polity)

3 Soshana Zuboff, The Age of Surveillance Capitalism (2019, Profile Books)

4 Patricia Pisters, The Neuro-Image: A Deleuzian Film-Philosophy of Digital Screen Culture (2012, Stanford UP), Nicole Falkenhayner, Media, Surveillance, and Affect: Narrating Feeling-States (2019, Routledge)

5 eg S Flynn and A McKay, eds, Spaces of Surveillance: States and Selfs (2017, Palgrave Macmillan), F Zappe and A S Gross, eds, Surveillance, Society, Culture (2020, Peter Lang), B Wasihun, ed., Narrating Surveillance - Überwachen erzählen (2020, Ergon).

6 Karen Louise Grova Søilen, "Safe is a Wonderful Feeling: Atmospheres of Surveillance and Contemporary Art" (2020) 18(2) Surveillance and Society, <https://ojs.library.queensu.ca/index.php/surveillance-and-society/index $>172$ 
However, this "work of mapping" is also challenging due to the multiplicity and variety of the many forms that are subsumed under the catch-all term of a culture of surveillance. Fields of interest range from the forms and technologies of surface monitoring, their connection to cinematic and narrative structures and their embeddeness in both religious and secular power structures ${ }^{7}$ to the forms and technologies of the combination of the digital economy's commodification of desires with data gathering.

So far, critical cultural studies interventions into the field of surveillance studies have been most productive when they engage with questions of visuality: the iconic quality of the surveillance camera, for example, has had the advantage of being easily linkable with cultural imaginaries of the all-seeing eye, be it the eye of god or the eye of a totalitarian state, which is in turn connected to the well-known figure of 'big broth$\mathrm{er}^{\prime}$. It lends itself to being linked to narrative practices, to cinematic experimentation, and it has produced images itself that have become embedded in social memory. ${ }^{8}$

More challenging, both for the artistic imagination itself as well as for its analysis and criticism, are the pervasive and multiple forms of data gathering and the work that is being done with this data, for example, in forms of machine learning and human-machine interactivity, which saturate our digital lifeworlds, but remain largely invisible to us. In contrast to the image of the surveillance camera, which immediately evokes a number of cultural associations, notions such as 'the data body' or 'the data shadow', which are an important aspect of the curated and algorithmised filter bubbles in which we exchange our views and form our image of the world, are characteristically vague and unplaceable. It is in this realm in which expertise from Cultural Studies faces its current challenge, as we have to find compelling images, forms of narration and representation for the analysis and criticism of a pervasive and pre-structuring aspect of the "diversity of affects, moods and atmospheres" that are produced by technologies and logics that are inherently difficult to represent in cultural forms of expression, such as narrative and images. Invisible surveillance, as a critical field in which scholars labour to bring its forms, strategies and dangers to public attention, thus shares a problematic similarity with the even more existential challenges of the climate crisis: it is abstract, accelerates over time, and challenges the representational imagination.

But just like climate crisis, forms of invisible surveillance demand our urgent critical attention because they have an immediate impact on our lives, and Cultural Studies scholars need to even increase their already strong conceptual openness to interdisciplinary approaches, by working together with social scientists, specialists in humanmachine interaction and, not least, data law specialists in order to find strategies to tackle the challenges of the present and the future.

7 Falkenhayner 2019, Pisters 2012, T Y Levin, U Frohne and P Weibel, eds, CTRL [SPACE]Rhetorics of Surveillance from Bentham to Big Brother (2002, MIT Press)

8 Stewart Garrett, Closed Circuits: Screening Narrative Surveillance (2015, Chicago UP), Nicole Falkenhayner, "Surveillance and Social Memory: Remembering Princess Diana with CCTV" (2016) 5(3) Humanities 73, 